\title{
Jejunal Diverticulosis: Presenting As Peritonitis
}

\author{
Vikas Chalotra', Puneet Bansal ${ }^{2}$, Natasha Nuna ${ }^{2}$, Shifali Joshi ${ }^{2}$, Sarbjeet Singh ${ }^{3}$, Aman Bharti ${ }^{4}$ \\ ${ }^{1}$ Assistant Professor, General Surgery, GGSMC\&H, Faridkot, ${ }^{2}$ PG Resident, General Surgery, GGSMC\&H, Faridkot, ${ }^{3}$ Associate Professor, General Surgery, \\ ${ }^{4}$ GGSMC\&H, Faridkot, Assistant Professor, General Medicine, GGSMC\&H, Faridkot.
}

\section{Abstract}

Jejunal diverticular perforation is a rare complication of jejunal diverticular disease and few cases have been reported in the literature. Jejunal diverticula have a prevalence of approximately $1 \%$ in the general population. Pathophysiology of chronic symptoms is related to either intestinal dyskinesia or bacterial overgrowth from blind loop syndrome due to stasis in diverticular lumen. Patients may develop malabsorption, steatorrhea, and megaloblastic anaemia from vitamin B12 deficiency. Conventional enteroclysis and CT enteroclysis is beneficial for diagnosis of jejunal diverticular disease. Jejunal diverticular perforation is very rare. Clinically, the diagnosis is challenging and mimics with other causes of acute abdomen. Presentation varies widely from asymptomatic to non specific symptoms to acute abdomen with catastrophic consequences. Here, we present a rare case of jejunal diverticular perforation.

Keywords: Jejunal diverticulosis, Small bowel diverticulosis, Acute abdomen, Diverticular perforation.

Corresponding Author: Dr. Vikas Chalotra, Assistant Professor, General Surgery, GGSMC\&H, Faridkot.

Received: September 2019

Accepted: September 2019

\section{Introduction}

Jejunal diverticular perforation is a rare entity with a prevalence of approximately $1 \%$ in the general population. Jejunal diverticula are the least common type of small bowel diverticula ${ }^{[1]}$ with incidence reported of 0.2 to $1.3 \%$ from autopsy studies ${ }^{[2]}$. Jejunal diverticula are pseudodiverticula described by Somerling in 1794. Gordinier and Shil performed the first operation for diverticula in 1906. ${ }^{[3]}$ Most of the cases of jejunal diverticula remain asymptomatic, only in 10 to $30 \%$ of patients complications are reported ${ }^{[4]}$ These include chronic abdominal pain, malabsorption, haemorrhage, diverticulitis, obstruction, abscess formation and rarely diverticular perforation. It is more common in men than women, 55\% in men compared to $42 \%$ in women ${ }^{[5]}$ Jejunal diverticula are usually multiple and localized to proximal jejunum (75\%), followed by the distal jejunum (20\%). They are frequently associated with disorders of intestinal mobility. Peritonitis caused by perforated jejunal diverticula can be localized and self limiting. The treatment of choice is segmental resection with primary anastomosis. ${ }^{[6]}$

\section{Case Report}

A 70 years female patient presented with the history of generalized pain abdomen since 4 days. Clinically patients look ill. On examination abdomen distended, guarding and rigidity was present. Patient febrile 100 degree Fahrenheit, pulse rate 110/mint, blood pressure $90 / 60 \mathrm{~mm}$ of $\mathrm{Hg}$ and respiratory rate 36/mint. Laboratory investigations revealed elevated white cell count (WBC $16000 \backslash \mathrm{mc} \mathrm{L}$ ), Hb 6gm\% normal RFTs and LFTs.

$\mathrm{X}$ ray abdomen erect showed multiple air fluid levels. $\mathrm{X}$ ray chest showed air under diaphragm[Figure 1]. Ultrasound abdomen showed moderate amount of fluid in peritoneal cavity with internal echoes. CT abdomen showed multiple jejunal diverticula.

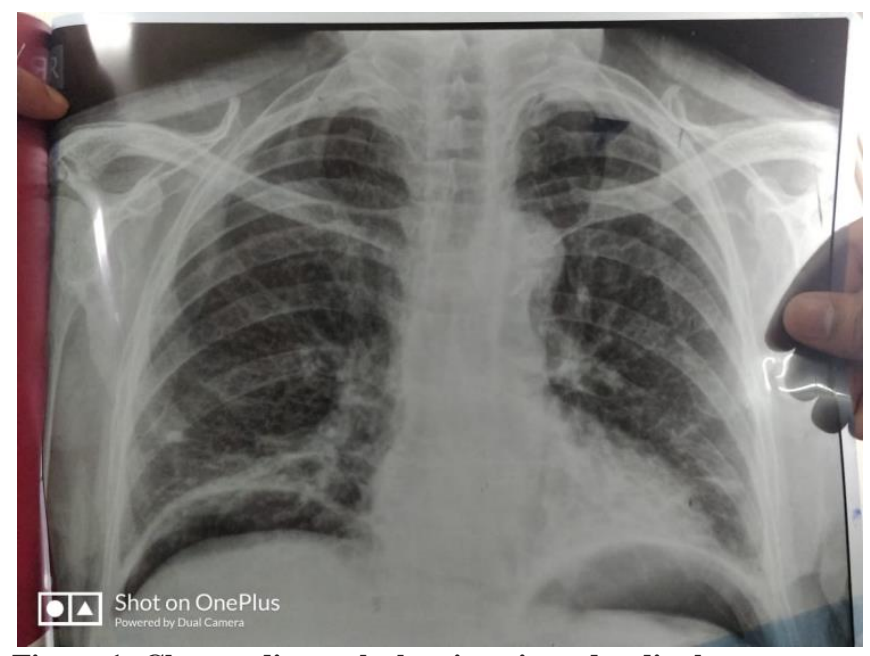

Figure 1: Chest radiograph showing air under diaphragm

Management started with intravenous fluid administration, iv antibiotics and blood transfusion was done. The patient underwent laparotomy which identified multiple jejunal diverticula in mesenteric border with a perforated diverticulum densely adhered with the loop of terminal 
ileum approximately $10 \mathrm{~cm}$ from ileocaecal junction. Multiple diverticula of size approximately1 to $1.5 \mathrm{~cm}$ were present about $15 \mathrm{~cm}$ from duodenojejunal flexure and length of involved jejunal segment was about $50 \mathrm{~cm}$. After adhesiolysis of jejunal diverticular perforation from terminal ileum, perforation measuring about $1 \mathrm{~cm}$ was found at the site of adhesion with iatrogenic perforation of terminal ileum about $2 \mathrm{~cm}$ in size and $10 \mathrm{~cm}$ from ileocaecal junction. The two perforation sites were closed primarily and oversewn[Figure 2], abdominal lavage was performed with loop ileostomy proximal to ileal perforation primary closure and abdominal drains were inserted.

Patient recovered well and discharged in satisfactory condition on $10^{\text {th }}$ post operative day.

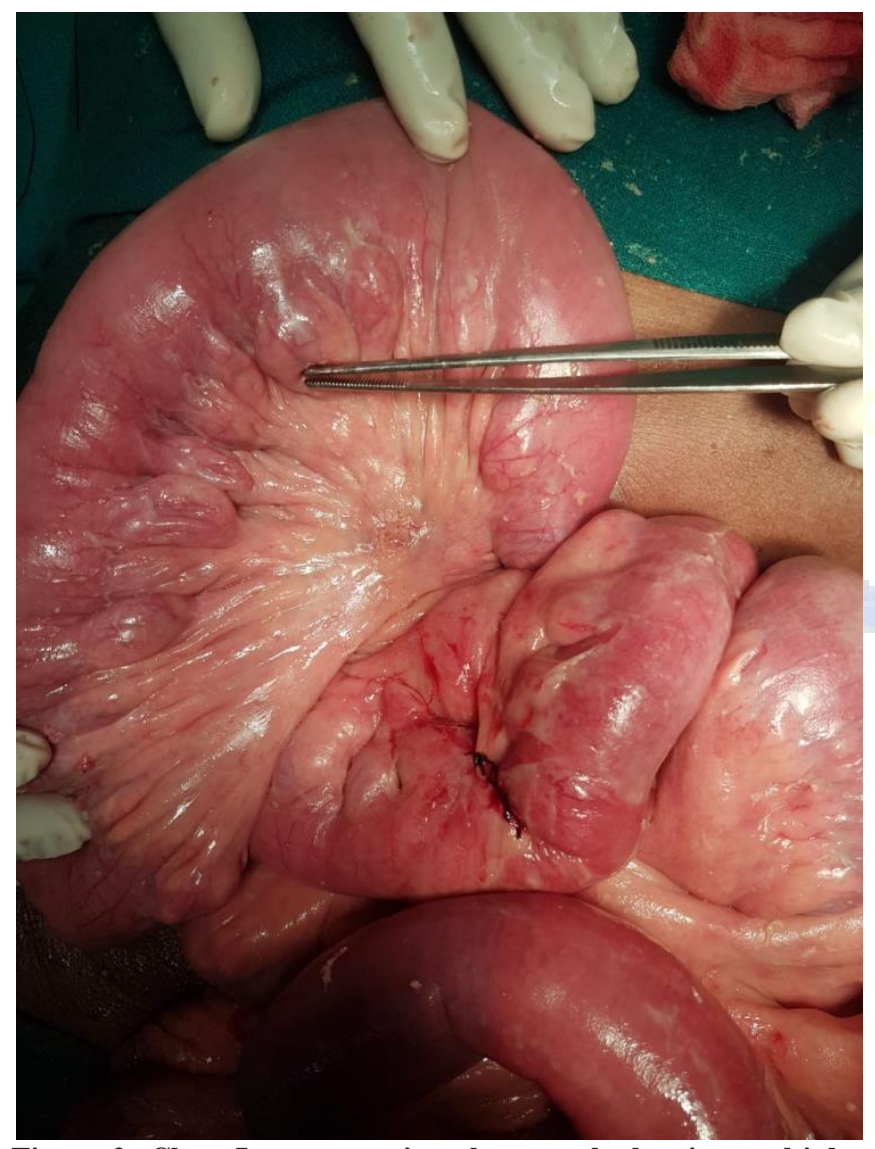

Figure 2: Chest Intra operative photograph showing multiple jejunal diverticuli with primary repair of perforated jejunal diverticulum.

\section{Discussion}

Jejunal diverticular disease is a rare pathology. Although true aetiology of diverticulosis is unknown, this condition is believed to develop from a combination of abnormal peristalsis, intestinal dyskinesis and high segmental intraluminal pressure. ${ }^{[7]}$ Majority of cases are clinically silent. When symptomatic, patients may describe a vague, chronic abdominal pain of varying severity. Acute complications are haemorrhage, obstruction and rarely perforation of the diverticula. ${ }^{[8]}$ Jejunal diverticulosis is a challenging disorder from a diagnostic perspective. Abdominal radiographs and/or chest radiographs demonstrate evidence of perforation. CT abdomen can identify the diverticula and reveals intra abdominal complications.

Management depends upon severity of symptoms .In stable patients with localized peritonitis non surgical management with intravenous antibiotics and percutaneous CT guided aspiration of localized intraperitoneal collection may be suitable. ${ }^{[9]}$ Current treatment of choice for perforated diverticuli causing generalized peritonitis is prompt laparotomy with segmental resection and primary anastomosis. The choice of treatment i.e resection or primary closure of perforation depends upon the length of the bowel affected by the diverticuli and patients perioperative condition. ${ }^{[10]}$.

In our case the decision to perform primary closure of jejunal diverticular perforation and terimal ileal perforation with proximal loop ileostomy was based on the age of the patient, extent of diverticulosis and perioperative condition of the patient which precluded a safe resection and anastomosis.

\section{References}

1. Zager JS, Garbus JE, Shaw JP, Cohen MG, Garber SM. Jejunal diverticulosis: A rare entity with multiple presentations, a series of cases. Dig Surg 2000;17:643-645.

2. Geroulakos G. Surgical problems of jejunal diverticulosis. Ann R Coll Surg Engl 1987;69-266-8.

3. Lempinen M, Salmela K, Kemppainen E. Jejunal diverticulosis: a potentially dangerous entity. Scand J Gastroentero. 2004;39 (9):90509.

4. Wilcox RD, Shatney CH. Surgical implications of jejunal diverticula. South Med J 1988:81:1386-91.

5. Tsiotos GG, Farnell MB, Ilstrup DM. Nonmeckelian jejunal or ileal diverticulosis: an analysis of 112 cases. Surgery. 1994;116:726-31.

6. Herrington JL., Jr Perforation of acquired diverticula of the jejunum and ileum: Analysis of reported cases. Surgery. 1962;51:426-33.

7. Koch AD, Schoon EJ. Extensive jejunal diverticulosis in a family, a matter of inheritance? Neth J Med 2007;65:154.

8. Woods K, Williams E, Melvin W, Sharp K. Acquired jejunoileal diverticulosis and its complications: A review of the literature. Am Surg 2008;74:849-54

9. Novak JS, Tobias J, Barkin JS: Nonsurgical management of acute jejunal diverticulitis: a review. Am J Gastroenterol. 1997, 92 (10): 1929-1931.

10. Mattioni R, Lolli E, Barbieri A, D’Ambrosi M. Perforated jejunal diverticulitis: Personal experience and diagnostic with therapeutical considerations. Ann Ital Chir 2000;71:95-8. 
Copyright: () the author(s), 2019. It is an open-access article distributed under the terms of the Creative Commons Attribution License (CC BY 4.0), which permits authors to retain ownership of the copyright for their content, and allow anyone to download, reuse, reprint, modify, distribute and/or copy the content as long as the original authors and source are cited.

How to cite this article: Chalotra V, Bansal P, Nuna N, Joshi S, Singh S, Bharti A. Jejunal Diverticulosis: Presenting As Peritonitis. Asian J. Med. Res. 2019;8(3):SG18-SG20.

DOI: dx.doi.org/10.21276/ajmr.2019.8.3.SG6

Source of Support: Nil, Conflict of Interest: None declared. 